University of Wollongong

Research Online

Australian Institute for Innovative Materials -

Papers

Australian Institute for Innovative Materials

2014

Impacts of crystal orientation of GaAs on the interfacial structures and electrical properties of Hf0.6La0.40x films

Tingting Jia

National Institute For Materials Science

Hideo Kimura

National Institute For Materials Science

Hongyang Zhao

Chinese Academy of Sciences

Qiwen Yao

University of Wollongong, qy75@uow.edu.au

Zhenxiang Cheng

University of Wollongong, cheng@uow.edu.au

See next page for additional authors

Follow this and additional works at: https://ro.uow.edu.au/aiimpapers

Part of the Engineering Commons, and the Physical Sciences and Mathematics Commons

Research Online is the open access institutional repository for the University of Wollongong. For further information contact the UOW Library: research-pubs@uow.edu.au 


\title{
Impacts of crystal orientation of GaAs on the interfacial structures and electrical properties of Hf0.6La0.40x films
}

\author{
Abstract \\ One of the major challenges in realizing the GaAs channel in the metal oxide semiconductor field effect \\ transistor is the degrading in electron transport properties at the interface between GaAs and the gate \\ oxide. In this study, $\mathrm{Hf}_{0.6 \mathrm{La}} \mathrm{L}_{4} \mathrm{O}_{\mathrm{x}}$ gate oxide films were deposited at a low temperature $\left(20{ }^{\circ} \mathrm{C}\right)$ on \\ $\mathrm{GaAs}(111) \mathrm{A}$ and $\mathrm{GaAs}(100)$ substrates by plasma enhanced atomic layer deposition. Microstructure \\ analysis indicates that residuals of gallium oxide, arsenic oxide, and As element remained at the interface

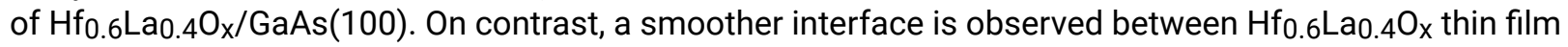 \\ and $\mathrm{GaAs}(111) \mathrm{A}$ substrate. Furthermore, a reduction of interfacial layer is observed in \\ $\mathrm{Hf}_{0.6} \mathrm{La}_{0.4 \mathrm{O}} / \mathrm{GaAs}(111) \mathrm{A}$. Electrical characterization of the metal-insulator-semiconductor Pt/ \\ $\mathrm{Hf}_{0.6 \mathrm{La}} \mathrm{LO}_{\mathrm{x}} / \mathrm{n}-\mathrm{GaAs}(111) \mathrm{A}$ capacitor indicated a reduction of Dit and leakage current compared with the \\ capacitor fabricated on $\mathrm{GaAs}(100)$.

\section{Keywords} \\ electrical, properties, hf0, 6la0, 4ox, structures, films, gaas, orientation, crystal, impacts, interfacial

\section{Disciplines} \\ Engineering | Physical Sciences and Mathematics

\section{Publication Details} \\ Jia, T., Kimura, H., Zhao, H., Yao, Q., Cheng, Z., Cheng, X. \& Yu, Y. (2014). Impacts of crystal orientation of

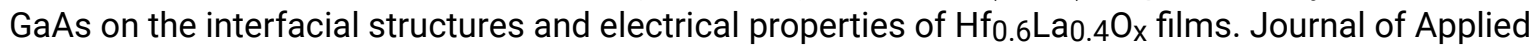 \\ Physics, 115 (13), 134101-1-134101-6.

\section{Authors} \\ Tingting Jia, Hideo Kimura, Hongyang Zhao, Qiwen Yao, Zhenxiang Cheng, Xinghong Cheng, and Yuehui \\ $\mathrm{Yu}$
}




\title{
Impacts of crystal orientation of GaAs on the interfacial structures and electrical properties of $\mathrm{Hf}_{0.6} \mathrm{La}_{0.4} \mathrm{O}_{\mathrm{x}}$ films
}

\author{
Tingting Jia, ${ }^{1}$ Hideo Kimura, ${ }^{1, a)}$ Hongyang Zhao, ${ }^{2}$ Qiwen Yao, ${ }^{3}$ Zhenxiang Cheng, ${ }^{3}$ \\ Xinghong Cheng, ${ }^{4}$ and Yuehui $\mathrm{Yu}^{4}$ \\ ${ }^{1}$ National Institute for Materials Science, 1-2-1 Sengen, Tsukuba, Ibaraki 305-0047, Japan \\ ${ }^{2}$ Shanghai Institute of Ceramics, Chinese Academy of Sciences, Dingxi Road 1295, Shanghai 200050, China \\ ${ }^{3}$ Institute for Superconducting and Electronic Materials, University of Wollongong, Squires Way, North \\ Wollongong, NSW 2500, Australia \\ ${ }^{4}$ State Key Laboratory of Functional Materials for Informatics, Shanghai Institute of Micro-system \\ and Information Technology, Chinese Academy of Sciences, Changning Road 865, Shanghai 200050, China
}

(Received 9 January 2014; accepted 19 March 2014; published online 1 April 2014)

\begin{abstract}
One of the major challenges in realizing the GaAs channel in the metal oxide semiconductor field effect transistor is the degrading in electron transport properties at the interface between GaAs and the gate oxide. In this study, $\mathrm{Hf}_{0.6} \mathrm{La}_{0.4} \mathrm{O}_{\mathrm{x}}$ gate oxide films were deposited at a low temperature $\left(200^{\circ} \mathrm{C}\right)$ on $\mathrm{GaAs}(111) \mathrm{A}$ and $\mathrm{GaAs}(100)$ substrates by plasma enhanced atomic layer deposition. Microstructure analysis indicates that residuals of gallium oxide, arsenic oxide, and As element remained at the interface of $\mathrm{Hf}_{0.6} \mathrm{La}_{0.4} \mathrm{O}_{\mathrm{x}} / \mathrm{GaAs}(100)$. On contrast, a smoother interface is observed between $\mathrm{Hf}_{0.6} \mathrm{La}_{0.4} \mathrm{O}_{\mathrm{x}}$ thin film and $\mathrm{GaAs}(111) \mathrm{A}$ substrate. Furthermore, a reduction of interfacial layer is observed in $\mathrm{Hf}_{0.6} \mathrm{La}_{0.4} \mathrm{O}_{\mathrm{x}} / \mathrm{GaAs}(111) \mathrm{A}$. Electrical characterization of the metal-insulator-semiconductor $\mathrm{Pt} / \mathrm{Hf}_{0.6} \mathrm{La}_{0.4} \mathrm{O}_{\mathrm{x}} / \mathrm{n}-\mathrm{GaAs}(111) \mathrm{A}$ capacitor indicated a reduction of $\mathrm{D}_{\mathrm{it}}$ and leakage current compared with the capacitor fabricated on GaAs(100). @ 2014 AIP Publishing LLC. [http://dx.doi.org/10.1063/1.4870446]
\end{abstract}

\section{INTRODUCTION}

With the continuous down scaling of complementary metal oxide semiconductor (CMOS) devices, searching for new materials to provide enhanced performance and stability for CMOS is in need. GaAs channel materials attracts considerable attentions for developing metal oxide semiconductor field effect transistors (MOSFETs) because of its higher intrinsic electron mobility and lower effective mass compared to Si. However, realizing GaAs's potential in this regard has proven to be difficult, partly due to the highly reactive GaAs surface. The complex native oxides of GaAs is quite unstable, it's structure and properties can be affected when exposed to light, moisture, or even with moderate heat treatments. The native oxide of GaAs presents a surface that is neither easily characterized nor passivated. A lot of efforts have been made to improving the interface quality of conventional high-k oxide GaAs. Recently, significant improvements of MOS transistor's performance have been achieved through replacing the surface orientation of traditional $\operatorname{GaAs}(100)$ or $\mathrm{In}_{0.53} \mathrm{Ga}_{0.47} \mathrm{As}$ by the polar $\mathrm{GaAs}(111) \mathrm{A}$ (Ga or In-rich) crystal face, in combination with thermal atomic layer deposition (ALD) of $\mathrm{Al}_{2} \mathrm{O}_{3} \cdot{ }^{1,2}$

$\mathrm{HfO}_{2}$ is one of the most promising high-k candidates for future CMOS devices, however, $\mathrm{HfO}_{2}$ on GaAs showed abnormal capacitance-voltage $(\mathrm{C}-\mathrm{V})$ characteristics with no accumulation observed, ${ }^{3}$ which is attributed to the native oxides induced interface pining between $\mathrm{GaAs}$ substrate and $\mathrm{HfO}_{2} \cdot{ }^{4}$ Fortunately, by doping La into $\mathrm{HfO}_{2}$ to form $\mathrm{HfLaO}_{\mathrm{x}}$ the performance of gate dielectrics can be enhanced

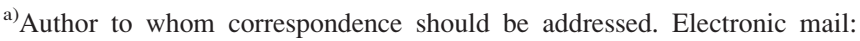
kimura.hideo@nims.go.jp.
}

considerably due to its high permittivity, ${ }^{5}$ relatively large conduction band (CB) offset, ${ }^{6,7}$ high crystallization temperature, ${ }^{8}$ and less Fermi-level pinning. ${ }^{9,10}$

GaAs has a zinc blende structure with double fcc cubic lattice of $\mathrm{Ga}$ atoms and As atoms. At the $\langle 111\rangle$ directions, atomic planes are occupied alternatively by $\mathrm{Ga}$ atoms and As atoms forming double layers, each atom has 3 bonds within the same double layer and one bond in the exterior of the double layer (Figure 1). The surfaces terminated by Ga atoms are called $\{111\} \mathrm{A}$, of which we will be focusing on in this work. On the other hand, along the $\langle 100\rangle$ directions the atomic planes are also occupied alternatively by $\mathrm{Ga}$ and As atoms. However, the planes are equidistant and each atom is symmetrically bonded with neighboring layers. The $\{111\} \mathrm{A}$ facets maybe more stable assuming that the three bonds (within the same double layer) are much more difficult to break. In this paper, we will discuss the influence of the

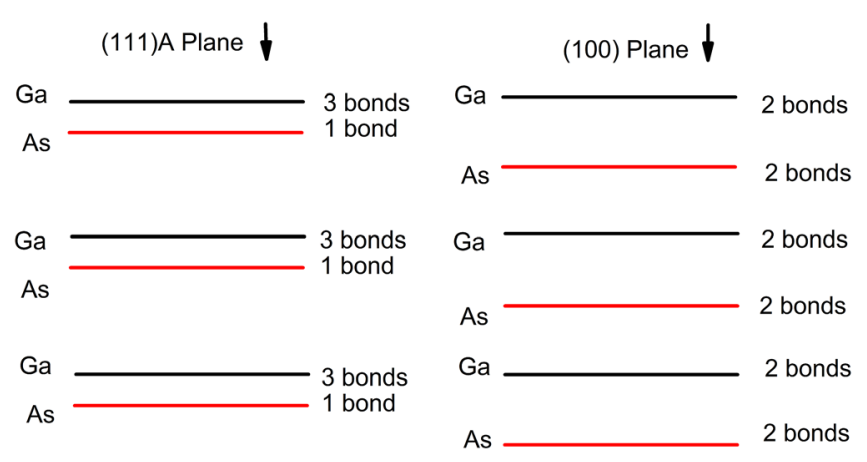

FIG. 1. Schematic atomic displacement of GaAs in (111)A and (100) orientation. 
crystal orientation of GaAs on the interfacial structures and the electrical properties of $\mathrm{Hf}_{0.6} \mathrm{La}_{0.4} \mathrm{O}_{\mathrm{x}}$ gate dielectrics.

\section{EXPERIMENT}

N-type GaAs substrates in (100) and (111)A orientation were used in this work. It is reported a high $\mathrm{La} /(\mathrm{La}+\mathrm{Hf})$ atomic ratio results in a better thermal stability than pure $\mathrm{HfO}_{2} \cdot{ }^{11}$ However, high $\mathrm{La} /(\mathrm{La}+\mathrm{Hf})$ atomic ratio would lead to a low deposition rate. Thus, in this work, we choose the La percentage around $40 \%$. The plasma enhanced ALD (PEALD) system was used to prepare $\mathrm{Hf}_{0.6} \mathrm{La}_{0.4} \mathrm{O}_{\mathrm{x}}$ dielectric films. GaAs substrates were cleaned by acetone and alcohol for $10 \mathrm{~min}$ and then in a dilute $\mathrm{HCl}$ solution $\left(\mathrm{HCl}: \mathrm{H}_{2} \mathrm{O}=1: 1\right)$ for $1 \mathrm{~min}$ to remove organic and native oxide, respectively. $\mathrm{Hf}\left[\mathrm{N}\left(\mathrm{CH}_{3}\right)\left(\mathrm{C}_{2} \mathrm{H}_{5}\right)\right]_{4}$ and $\mathrm{La}\left[\mathrm{N}(\mathrm{TMS})_{2}\right]_{3}$ were used as metal precursors, and $\mathrm{O}_{2}$ plasma served as oxidant. The growth temperature was set to $200^{\circ} \mathrm{C}$. The total deposition of $\mathrm{Hf}_{0.6} \mathrm{La}_{0.4} \mathrm{O}_{\mathrm{x}}$ film on GaAs substrate consists of 10 cycles of alternately deposited $\mathrm{La}_{2} \mathrm{O}_{3}-\mathrm{HfO}_{2}$ nanolaminates and 5 cycles of $\mathrm{HfO}_{2}$ cap layer to avoid hydrolyzed of La-component when exposed in air. Each nanolaminate cycle consists of three sub-cycles $\mathrm{La}_{2} \mathrm{O}_{3}$ and one sub-cycle $\mathrm{HfO}_{2}: 3$ cycles of $\mathrm{La}_{2} \mathrm{O}_{3}$ is first deposited on GaAs surface and then followed by 1 cycle $\mathrm{HfO}_{2}$. As we known, due to the interfacial traps between the dielectric film and GaAs substrate which induced interface pining near the midgap, directly deposited high-k gate dielectrics on GaAs sometimes even showed abnormal capacitance voltage $(\mathrm{C}-\mathrm{V})$ characteristics with no accumulation observed. $^{12}$ Chang et al. ${ }^{13}$ investigated the impacts of post-deposition annealing (PDA) on the GaAs MOS device; they found that post annealing lead to significant reduction of interfacial state density $\left(D_{i t}\right)$ near the midgap. Moreover, the post annealing higher than $500^{\circ} \mathrm{C}$ would result in a charge transfer effect between $\mathrm{La}$ and $\mathrm{Hf}$ and improve the Hf-La-O bonding state. ${ }^{14}$ However, annealing temperature higher than $550{ }^{\circ} \mathrm{C}$ would lead to a thicker interfacial layer which deteriorates the interfacial quality. ${ }^{12}$ Therefore, we carried out a PDA in a $\mathrm{N}_{2}$ ambient at $500^{\circ} \mathrm{C}$ for $1 \mathrm{~min}$ by the rapid thermal annealing (RTA) technique. Metal-insulator-semiconductor (MIS) capacitors were formed with a Pt top electrodes formed by shadow mask sputtering, and a bottom electrode formed by blanket sputtering of Pt. Post metallization annealing (PMA) in forming gas $\left(5 \% \mathrm{H}_{2} / 95 \% \mathrm{~N}_{2}\right)$ at $450{ }^{\circ} \mathrm{C}$ was performed to form ohmic contact. The microstructure and chemical states were analyzed by cross-sectional high resolution transmission electron microscopy (HRTEM) and X-ray photoelectron spectroscopy (XPS). High frequency capacitance-voltage (C-V) and leakage current-voltage $(\mathrm{J}-\mathrm{V})$ measurements of the MIS capacitors were carried out using an Agilent B1500A Semiconductor Device Analyzer.

\section{RESULTS AND DISCUSSION}

\section{A. Interfacial microstructures}

Interfacial morphology was studied using crosssectional TEM. It is shown in Figure 2 that the interface of the $\mathrm{Hf}_{0.6} \mathrm{La}_{0.4} \mathrm{O}_{\mathrm{x}}$ on $\mathrm{GaAs}(111) \mathrm{A}$ is smoother than that on $\mathrm{GaAs}(100)$. A reduction of interfacial layer is observed on the GaAs(111)A-substrate film. The thickness of the $\mathrm{Hf}_{0.6} \mathrm{La}_{0.4} \mathrm{O}_{\mathrm{x}}$ film is $9.6 \mathrm{~nm}$ and $8.2 \mathrm{~nm}$ on $\mathrm{GaAs}(100)$ and GaAs(111)A, respectively. The reduction of the film thickness was partially due to the reduction of the interfacial layer, and the deposition rate was found to be different on the GaAs substrates with different orientations.

To further investigate the chemical structure of the interface between the $\mathrm{Hf}_{0.6} \mathrm{La}_{0.4} \mathrm{O}_{\mathrm{x}}$ films and the GaAs substrates, XPS measurements were performed to determine the interfacial structures. XPS was performed ex-situ using a monochromatic $\mathrm{Al} \mathrm{K} \alpha \mathrm{X}$-ray source at a power of $150 \mathrm{~W}$. The binding energy was calibrated with the position of $\mathrm{C} 1 \mathrm{~s}$ peak at $284.8 \mathrm{eV}$. According to the XPS analysis, the atomic ratio of $\mathrm{La} /(\mathrm{La}+\mathrm{Hf})$ in $\mathrm{Hf}_{0.6} \mathrm{La}_{0.4} \mathrm{O}_{\mathrm{x}}$ is $40.9 \%$ and $41.9 \%$ for the film deposited on $\operatorname{GaAs}(100)$ and $\operatorname{GaAs}(111) \mathrm{A}$, respectively. Arsenic oxides were commonly observed in the XPS results of the thin films deposited on GaAs(100), which was generally located at $43.20 \mathrm{eV}, 43.98 \mathrm{eV}$, and $44.86 \mathrm{eV}$ corresponding to $\mathrm{AsO}, \mathrm{As}_{2} \mathrm{O}_{3}$, and $\mathrm{As}_{2} \mathrm{O}_{5}$, respectively. ${ }^{15}$ The As $3 \mathrm{~d}$ spectra of $\mathrm{Hf}_{0.6} \mathrm{La}_{0.4} \mathrm{O}_{\mathrm{x}}$ on $\mathrm{GaAs}(111) \mathrm{A}$ is shown in Figure 3(a), besides the strongest peak of As-Ga bond, there is a weak peak at $43.20 \mathrm{eV}$ which is ascribed to AsO. The low coordinated oxidation state is corresponding to Arsenic surface states such as dimers and possibly dangling bonds. ${ }^{18}$ There is no As element detected in this sample. In the As $3 \mathrm{~d}$ core level spectra of $\mathrm{Hf}_{0.6} \mathrm{La}_{0.4} \mathrm{O}_{\mathrm{x}}$ on $\mathrm{GaAs}(100)$ as shown in Figure 3(c), besides the As-Ga bond, two peaks located at $43.57 \mathrm{eV}$, and $44.47 \mathrm{eV}$ related to Arsenic oxide was

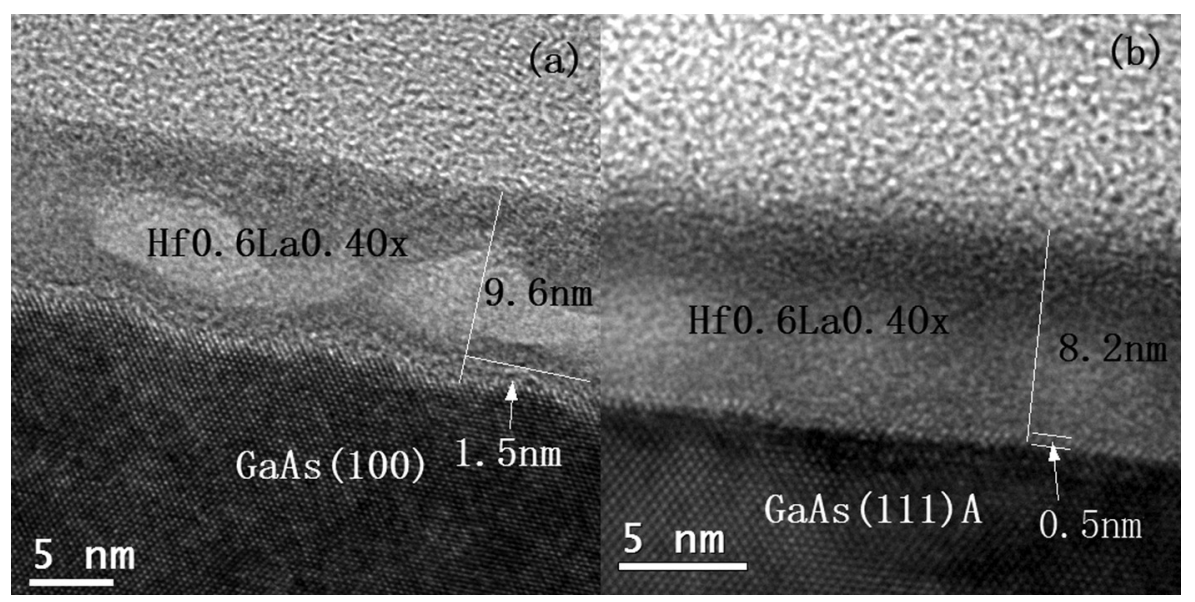

FIG. 2. Cross-sectional TEM images of interface structure between $\mathrm{Hf}_{0.6} \mathrm{La}_{0.4} \mathrm{O}_{\mathrm{x}}$ film and (a) $\mathrm{GaAs}(100)$ and (b) GaAs(111)A. 

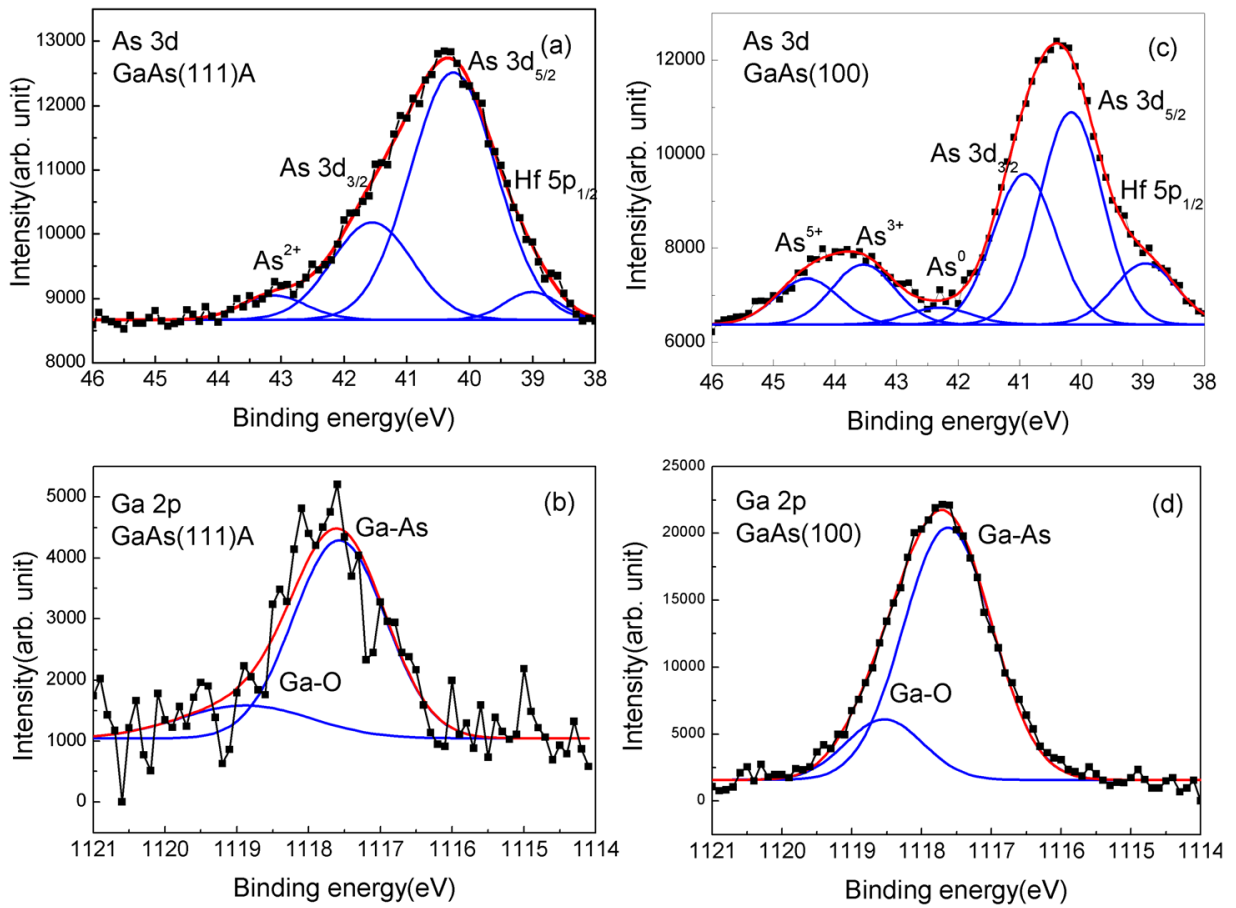

FIG. 3. XPS As $3 \mathrm{~d}$ and Ga $2 \mathrm{p}$ core level spectra for $\mathrm{Hf}_{0.6} \mathrm{La}_{0.4} \mathrm{O}_{\mathrm{x}}$ films on GaAs(111)A ((a) and (b)) and $\operatorname{GaAs}(100)((c)$ and (d)). detected, indicating the existence of residual $\mathrm{As}_{2} \mathrm{O}_{3}$ and $\mathrm{As}_{2} \mathrm{O}_{5}$ at $\mathrm{Hf}_{0.6} \mathrm{La}_{0.4} \mathrm{O}_{\mathrm{x}} / \mathrm{GaAs}(100)$ interface. Furthermore, the As element at $42.28 \mathrm{eV}$ was also detected at the interface due to the exchange reaction between GaAs substrate and Arsenic oxide. ${ }^{16}$ For the Ga $2 \mathrm{p}$ spectra (Figures 3(b) and $3(d)$ ), gallium oxide was detected in both of the samples. There are two possible causes responsible for the $\mathrm{Ga}-\mathrm{O}$ bond, one is the residual $\mathrm{Ga}_{2} \mathrm{O}_{3}$ exists at the interface; the other is that the $\mathrm{Ga}_{2} \mathrm{O}_{3}$ is formed by the scattering during ALD growth and PDA process. Although there are peaks from As-O and Ga-O bonds detected in both of the samples, we observe a reduction of $\mathrm{Ga}_{2} \mathrm{O}_{3}$ and Arsenic oxides in $\mathrm{Hf}_{0.6} \mathrm{La}_{0.4} \mathrm{O}_{\mathrm{x}} / \mathrm{GaAs}(111) \mathrm{A}$. Based on these XPS results, the ALD growth on GaAs(111)A substrate would minimum amount of interfacial $\mathrm{Ga}_{2} \mathrm{O}_{3}$ and arsenic oxides which is responsible for causing large $\mathrm{D}_{\mathrm{it}}$ and Fermi level pinning. ${ }^{12}$ Thus, GaAs(111)A would be more favorable as a substrate for high-k dielectrics.

\section{B. Band alignment of $\mathrm{Hf}_{0.6} \mathrm{La}_{0.4} \mathrm{O}_{\mathrm{x}} / \mathrm{GaAs}(111) \mathrm{A}$}

One of the most fundamental physical properties for characterizing a semiconductor interface is the band alignment. In order to determine the $\mathrm{CB}$ offset value, the band gap $\left(\mathrm{E}_{\mathrm{g}}\right)$ energies of the $\mathrm{Hf}_{0.6} \mathrm{La}_{0.4} \mathrm{O}_{\mathrm{x}}$ films on $\mathrm{GaAs}(111) \mathrm{A}$ were determined from $\mathrm{O}$ 1s energy loss for photoelectrons. In Figure 4(a), the onset of band to band excitation which corresponds to $E_{g}$ is defined as an intercept of linear extrapolation of the leading edge to the background level. The $\mathrm{E}_{\mathrm{g}}$ was determined to be $4.33 \mathrm{eV}$ for the $\mathrm{Hf}_{0.6} \mathrm{La}_{0.4} \mathrm{O}_{\mathrm{x}}$ film. To study the relationship of the energy band for $\mathrm{Hf}_{0.6} \mathrm{La}_{0.4} \mathrm{O}_{\mathrm{x}} / \mathrm{GaAs}(111) \mathrm{A}$, the valence band (VB) spectra were measured for the $\mathrm{Hf}_{0.6} \mathrm{La}_{0.4} \mathrm{O}_{\mathrm{x}}$ films grew on $\mathrm{GaAs}(111) \mathrm{A}$ substrates, as well as the bare GaAs(111)A samples, after the $\mathrm{Ar}^{+}$etching of the XPS measurements. The measurement is based on the assumption that the energy difference between the core level and VB edge of the GaAs substrate remains constant with/without the deposition of $\mathrm{Hf}_{0.6} \mathrm{La}_{0.4} \mathrm{O}_{\mathrm{x}}$ films. ${ }^{17}$ Figure 4(b) shows the VB spectra of $\mathrm{GaAs}(111) \mathrm{A}$ substrate and the as-received $\mathrm{Hf}_{0.6} \mathrm{La}_{0.4} \mathrm{O}_{\mathrm{x}}$ film on GaAs(111)A. In our work, the As 3d peak and VB edge from the GaAs(111)A substrate were chosen as the reference to determine the VB offset between the $\mathrm{Hf}_{0.6} \mathrm{La}_{0.4} \mathrm{O}_{\mathrm{x}}$ film and GaAs(111)A substrate. The core level positions and VB maximum of bulk materials combined with core level difference of heterojunction are used to calculate the VB offset. The VB maximum is determined by using a linear extrapolation method. ${ }^{17}$ The $\mathrm{Hf}_{0.6} \mathrm{La}_{0.4} \mathrm{O}_{\mathrm{x}} \mathrm{VB}$ offset can be obtained by eliminating the VB spectra of the GaAs substrate from the $\mathrm{Hf}_{0.6} \mathrm{La}_{0.4} \mathrm{O}_{\mathrm{x}} \mathrm{VB}$ spectrum using the following formula:

$$
\begin{aligned}
\triangle E_{v}= & \left(E_{C L}^{A s 3 d}-E_{v}^{\mathrm{GaAs}}\right)_{\mathrm{GaAs}}-\left(\mathrm{E}_{C L}^{H f 4 f}-E_{v}^{H L O}\right)_{H L O} \\
& +\left(E_{C L}^{H f 4 f}-\mathrm{E}_{\mathrm{CL}}^{\mathrm{As} 3 \mathrm{~d}}\right)_{H L O / G a A s},
\end{aligned}
$$

where $E_{C L}^{A s 3 d}$ and $\mathrm{E}_{C L}^{H f} 4 f$ are the binding energy of As $3 \mathrm{~d}$ and Hf $4 \mathrm{f}, E_{v}^{\mathrm{GaAs}}$ and $E_{v}^{H L O}$ are the VB maximum of GaAs and $\mathrm{Hf}_{0.6} \mathrm{La}_{0.4} \mathrm{O}_{\mathrm{x}} / \mathrm{GaAs}$. Consequently, the $\mathrm{VB}$ offset value is $1.61 \mathrm{eV}$ obtained at the top of the VB maximum at the $\mathrm{Hf}_{0.6} \mathrm{La}_{0.4} \mathrm{O}_{\mathrm{x}} / \mathrm{GaAs}$ interface. The $\mathrm{CB}$ offset can be evaluated by subtracting the $\mathrm{VB}$ offset and the $\mathrm{E}_{\mathrm{g}}$ of $\mathrm{GaAs}$ substrate from the $\mathrm{E}_{\mathrm{g}}$ of $\mathrm{Hf}_{0.6} \mathrm{La}_{0.4} \mathrm{O}_{\mathrm{x}}$ film by the following formula: ${ }^{18}$

$$
\triangle E_{c}^{H i g h-k / G a A s}=\triangle E_{g}^{H i g h-k}-\triangle E_{v}^{H i g h-k / G a A s}-\triangle E_{g}^{G a A s},
$$

where $\triangle E_{c}^{H i g h-k / G a A s}$ represents the CB offset between high$\mathrm{k}$ films and GaAs, $\triangle E_{g}^{H i g h-k}$ is the band gap of high-k, $\triangle E_{v}^{H i g h-k / G a A s}$ is the $\mathrm{VB}^{g}$ offset between high-k and GaAs, and $\triangle E_{g}^{G a A s}$ is the band gap of GaAs which is $1.42 \mathrm{eV}$. Consequently, the $\mathrm{Hf}_{0.6} \mathrm{La}_{0.4} \mathrm{O}_{\mathrm{x}} / \mathrm{GaAs}(111) \mathrm{A} \quad \mathrm{CB}$ offset $\left(\triangle E_{c}^{H i g h-k / G a A s}\right)$ is calculated to be $1.30 \mathrm{eV}$. The energy band diagram for $\mathrm{Hf}_{0.6} \mathrm{La}_{0.4} \mathrm{O}_{\mathrm{x}} / \mathrm{GaAs}(111) \mathrm{A}$ stack is obtained as Figure 4(c). 

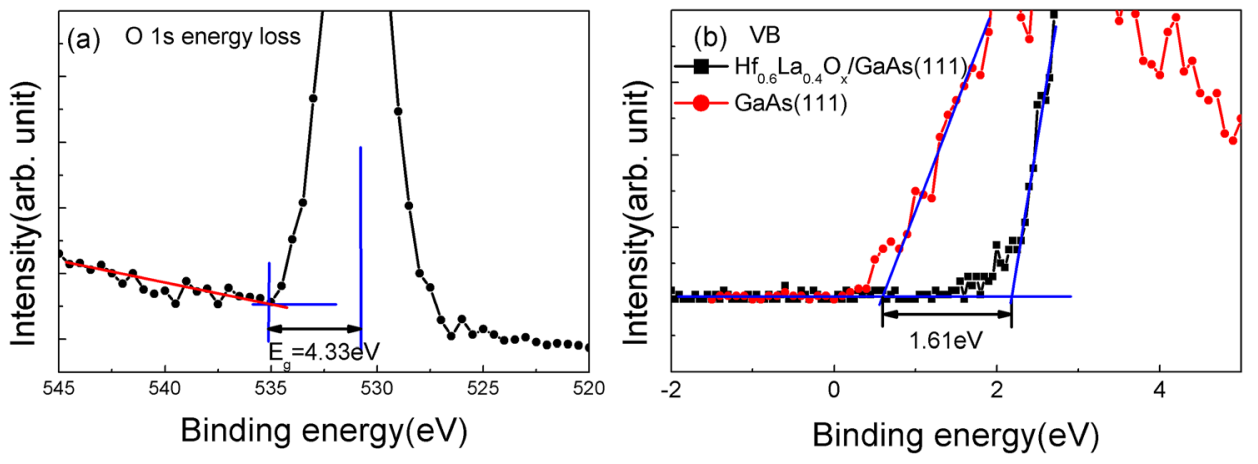

(c)

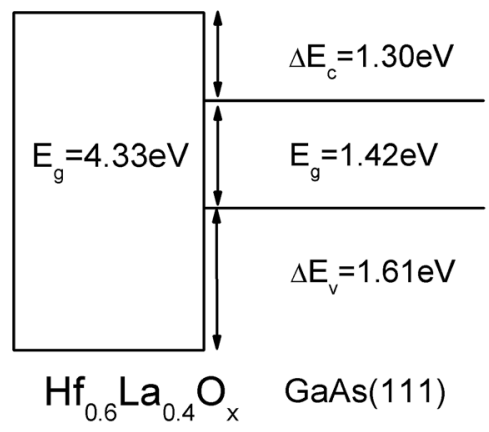

\section{Electrical properties}

The capacitance-voltage $(\mathrm{C}-\mathrm{V})$ and the leakage current density-voltage $(\mathrm{J}-\mathrm{V})$ of $\mathrm{Pt} / \mathrm{Hf}_{0.6} \mathrm{La}_{0.4} \mathrm{O}_{\mathrm{x}} / \mathrm{n}-\mathrm{GaAs}(111) \mathrm{A}$ and $\mathrm{Pt} / \mathrm{Hf}_{0.6} \mathrm{La}_{0.4} \mathrm{O}_{\mathrm{x}} / \mathrm{n}-\mathrm{GaAs}(100)$ MIS capacitors were measured using a HP4194A impedance analyzer and an Agilent $4156 \mathrm{C}$ precision semiconductor parameter analyzer, respectively. As shown in Figure 5(a), the C-V measurements were performed at $10 \mathrm{kHz}$ and $1 \mathrm{MHz}$. In the top inset of Figure 5(a), the inversion, depletion, and accumulation modes are clearly shown in the $\mathrm{C}-\mathrm{V}$ curves, a frequency dispersion $\left(\triangle C_{o x}\right)$ in accumulation is also observed, which suggests that a high leakage current exists in both of the samples while applying high voltage. $\triangle C_{o x}$ between $10 \mathrm{kHz}$ and $1 \mathrm{MHz}$ is evaluated as $10.1 \%$ and $16.2 \%$ for $\mathrm{Hf}_{0.6} \mathrm{La}_{0.4} \mathrm{O}_{\mathrm{x}} / \mathrm{GaAs}(111) \mathrm{A}$
$(10.1 \%)$ and $\mathrm{Hf}_{0.6} \mathrm{La}_{0.4} \mathrm{O}_{\mathrm{x}} / \mathrm{GaAs}(100)$, respectively. In GaAs/high-k system, the complex nature of the interface with a high density of interface states $\left(D_{i t}\right)$ can exhibit an interface state capacitance $\left(C_{i t}\right)$ that contributes significantly to the measured capacitance. The existence of $\mathrm{C}_{\mathrm{it}}$ is also responsible for the frequency dispersion which is origin from a low resistivity interfacial layer adjacent to the interface. ${ }^{19}$ The reduction of frequency dispersion in $\mathrm{Hf}_{0.6} \mathrm{La}_{0.4} \mathrm{O}_{\mathrm{x}} /$ $\mathrm{GaAs}(111) \mathrm{A}$ indicates a suppression of the interface traps. In order to remove the effect of leakage current and interface states, ${ }^{20,21}$ an equivalent circuit is used to correct the capacitance as shown in the left bottom of Figure 5(a). The actual frequency independent capacitance $\left(\mathrm{C}_{\text {ture }}\right)$ can be calculated as follows: ${ }^{22}$

$$
C_{\text {ture }}=\frac{\left(\omega^{2} C_{m} C_{E}-G_{m}^{2}-\omega^{2} C_{m}^{2}\right)\left(G_{m}^{2}+\omega^{2} C_{m}^{2}\right) C_{E}}{\left(\omega^{2} C_{E}^{2}\right)\left[G_{m}\left(1-R_{s}^{\prime} G_{m}\right)-\omega^{2} R_{s}^{\prime} C_{m}^{2}\right]^{2}+\left(\omega^{2} C_{m}^{2}+G_{m}^{2}-\omega^{2} C_{m} C_{E}\right)^{2}}
$$

where $R_{s}^{\prime}=\frac{G_{m a}}{G_{m a}^{2}+\omega^{2} C_{m a}^{2}}$ and $C_{E}=\frac{-C_{o x}\left(G_{m a}^{2}+\omega^{2} C_{m a}^{2}\right)}{\omega^{2}\left(C_{m a}^{2}-C_{o x} C_{m a}\right)+G_{m a}^{2}}, \mathrm{C}_{\mathrm{m}}$ and $\mathrm{G}_{\mathrm{m}}$ are the measured capacitance and conductance, respectively. $\mathrm{C}_{\mathrm{ma}}$ and $\mathrm{G}_{\mathrm{ma}}$ represent the measured capacitance and conductance in strong accumulation, respectively. $\mathrm{C}_{\mathrm{ox}}$ is the maximum accumulation capacitance, $\omega$ denotes angular frequency. From the actual frequency independent device capacitance curves as shown in Figure 5(a), the $\mathrm{C}_{\mathrm{ox}}$ of $\mathrm{Pt} / \mathrm{Hf}_{0.6} \mathrm{La}_{0.4} \mathrm{O}_{\mathrm{x}} / \mathrm{n}-\mathrm{GaAs}(111) \mathrm{A}$ capacitor is $2.5 \mu \mathrm{F} / \mathrm{cm}^{2}$ higher than that of the $\mathrm{Pt} / \mathrm{Hf}_{0.6} \mathrm{La}_{0.4} \mathrm{O}_{\mathrm{x}} / \mathrm{n}-\mathrm{GaAs}(100)\left(2.3 \mu \mathrm{F} / \mathrm{cm}^{2}\right)$. The slope of the $\mathrm{C}-\mathrm{V}$ curve of $\mathrm{Hf}_{0.6} \mathrm{La}_{0.4} \mathrm{O}_{\mathrm{x}} / \mathrm{GaAs}(111) \mathrm{A}$ is greater than that of $\mathrm{Hf}_{0.6} \mathrm{La}_{0.4} \mathrm{O}_{\mathrm{x}} / \mathrm{GaAs}(100)$, which indicates that the interface trap density is lower in $\mathrm{Hf}_{0.6} \mathrm{La}_{0.4} \mathrm{O}_{\mathrm{x}} /$ $\mathrm{GaAs}(111)$. However, the $\mathrm{C}-\mathrm{V}$ curve of $\mathrm{Hf}_{0.6} \mathrm{La}_{0.4} \mathrm{O}_{\mathrm{x}} /$ $\mathrm{GaAs}(111) \mathrm{A}$ in depletion region stretches out indicates a presence of slow interface states in GaAs band gap. The equivalent oxide thickness (EOT) for $\mathrm{Hf}_{0.6} \mathrm{La}_{0.4} \mathrm{O}_{\mathrm{x}}$ film was calculated by $\mathrm{EOT}=\varepsilon_{\mathrm{Ox}} \varepsilon_{0} \mathrm{~A} / \mathrm{C}_{\mathrm{ox}}$, where $\varepsilon_{\mathrm{Ox}}$ and $\varepsilon_{0}$ are the dielectric constants for $\mathrm{SiO}_{2}$ and the vacuum, respectively. It turns out that the EOT value of $\mathrm{Hf}_{0.6} \mathrm{La}_{0.4} \mathrm{O}_{\mathrm{x}}$ on $\mathrm{GaAs}(111) \mathrm{A}$ and $\operatorname{GaAs}(100)$ is about $1.4 \mathrm{~nm}$ and $1.5 \mathrm{~nm}$, the corresponding $\mathrm{k}$ value of as-deposited $\mathrm{Hf}_{0.6} \mathrm{La}_{0.4} \mathrm{O}_{\mathrm{x}}$ film is 22.8 and 24.9, respectively. The corresponding interfacial state density $\left(D_{i t}\right)$ of the samples is extracted by the 

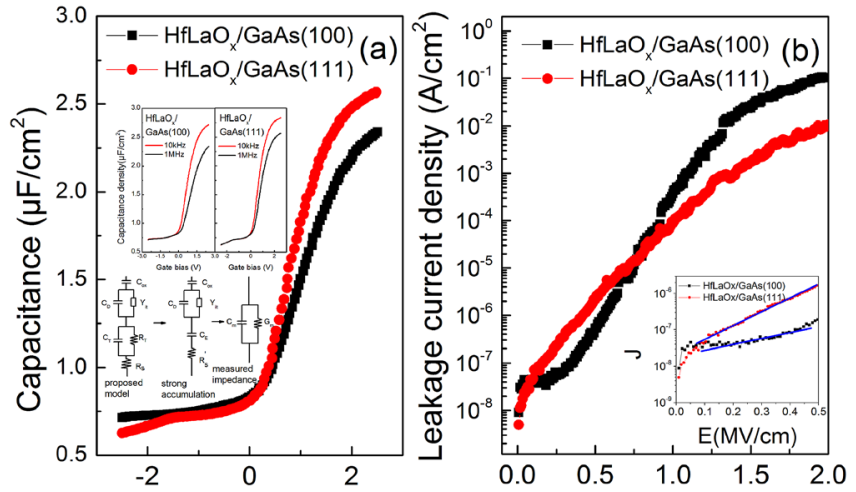

Gate bias $(\mathrm{V})$

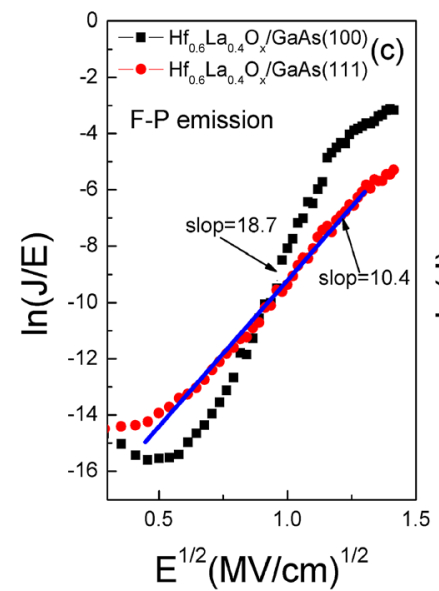

Gate bias(V)

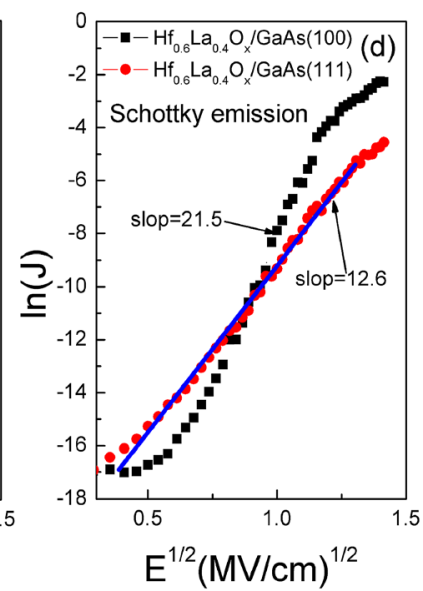

FIG. 5. (a) Capacitance-voltage (C-V) curves of $\mathrm{Pt} / \mathrm{Hf}_{0.6} \mathrm{La}_{0.4} \mathrm{O}_{\mathrm{x}} /$ $\mathrm{GaAs}(111) \mathrm{A} / \mathrm{Pt}$ and $\mathrm{Pt} / \mathrm{Hf}_{0.6} \mathrm{La}_{0.4} \mathrm{O}_{\mathrm{x}} / \mathrm{GaAs}(100) / \mathrm{Pt}$ capacitors. The inset on the top is the $\mathrm{C}-\mathrm{V}$ curves measured at $10 \mathrm{kHz}$ and $1 \mathrm{MHz}$; and the bottom inset is the equivalent circuit model; (b) leakage current density-voltage $(\mathrm{J}-\mathrm{V})$ curves. The inset is the corresponding J-E curves at low electric field from 0.1 to $0.5 \mathrm{MV} / \mathrm{cm}$; (c) the curve of $\ln (\mathrm{J} / \mathrm{E}$ ) versus square root of the electric field $\left(\mathrm{E}^{1 / 2}\right)$ and $(\mathrm{d})$ the curve of $\ln (\mathrm{J})$ versus square root of the electric field $\left(\mathrm{E}^{1 / 2}\right)$ for the as-deposited $\mathrm{Hf}_{0.6} \mathrm{La}_{0.4} \mathrm{O}_{\mathrm{x}}$ films on $\mathrm{GaAs}(111) \mathrm{A}$ and (100).

conductance method. ${ }^{23}$ The $\mathrm{D}_{\text {it }}$ at midgap of the band gap energy is $1.62 \times 10^{12} \mathrm{eV}^{-1} \mathrm{~cm}^{-2}$ and $3.25 \times 10^{12} \mathrm{eV}^{-1} \mathrm{~cm}^{-2}$ for $\mathrm{Hf}_{0.6} \mathrm{La}_{0.4} \mathrm{O}_{\mathrm{x}} / \mathrm{GaAs}(111) \mathrm{A}$ and $\mathrm{Hf}_{0.6} \mathrm{La}_{0.4} \mathrm{O}_{\mathrm{x}} / \mathrm{GaAs}(100)$, respectively. Lower $\mathrm{D}_{\text {it }}$ value for $\mathrm{Hf}_{0.6} \mathrm{La}_{0.4} \mathrm{O}_{\mathrm{x}}$ film on GaAs(111)A indicated a better interface quality. This result is consisting with the TEM and XPS result. We have to note that the $\mathrm{D}_{\mathrm{it}}$ is still as high as $\sim 10^{12}$ order of magnitude which attribute to the $\mathrm{Ga}_{2} \mathrm{O}_{3}$ in the interfacial layer. ${ }^{12}$

The leakage current density $(\mathrm{J})$ as a function of the gate bias (V) of $\mathrm{Hf}_{0.6} \mathrm{La}_{0.4} \mathrm{O}_{\mathrm{x}}$ films is shown in Figure 5(b). It is clear that the $\mathrm{Hf}_{0.6} \mathrm{La}_{0.4} \mathrm{O}_{\mathrm{x}}$ film deposited on $\mathrm{GaAs}(100)$ has a lower leakage current density than on GaAs(111)A when the applied field is lower than $1 \mathrm{~V}$. However, leakage current density in $\mathrm{Hf}_{0.6} \mathrm{La}_{0.4} \mathrm{O}_{\mathrm{x}} / \mathrm{GaAs}(100)$ is higher while the electric field is higher than $1 \mathrm{~V}$. To further understand the behavior of leakage current, the current conduction mechanism of the $\mathrm{Hf}_{0.6} \mathrm{La}_{0.4} \mathrm{O}_{\mathrm{x}}$ films was investigated. In dielectric films, there are several possible mechanisms responsible for the leakage current, such as Freckle-Poole (F-P) emission, Schottky emission, Fowler-Nordheim tunneling, ohmic transportation, ionic conduction, and a space charge limited current.
For F-P emission, the current density is given by ${ }^{24}$

$$
J_{F P}=J_{0} \exp \left[\frac{q\left(-\varphi_{F P}+\sqrt{q E / \pi \varepsilon_{0} \varepsilon_{r}}\right)}{k T}\right] .
$$

In addition, the current density due to Schottky emission can be expressed as follows:

$$
J_{S}=A^{*} T^{2} \exp \left[\frac{q\left(-\varphi_{B}+\sqrt{q E / 4 \pi \varepsilon_{0} \varepsilon_{r}}\right)}{k T}\right] .
$$

Moreover, ohmic transportation can be expressed as

$$
J_{O}=A E \exp \left(\triangle E_{a c} / k T\right),
$$

where $\mathrm{J}_{\mathrm{O}}$ represents low field current density, $\mathrm{A}^{*}$ is Richardson constant, q denotes electronic charge, $\varepsilon_{r}$ represents dynamic dielectric constant, $\mathrm{k}$ is Boltzmann constant, $\mathrm{T}$ denotes absolute temperature, $\varphi_{F P}$ is the height of trap potential well, $\varphi_{B}$ represents contact potential battier, $\mathrm{A}$ is a constant, $\triangle E_{a c}$ represents the activation energy of the electron, and $\mathrm{E}$ denotes applied electric field. The inset of Figure 5(b) plots J vs. E at low electric field from 0.1 to $0.5 \mathrm{MV} / \mathrm{cm}$, a linear shape suggests that the conduction mechanism at low electric field is ohmic transportation which is due to the injection from substrate. Figures 5(c) and 5(d) show a logarithmic current density divided by the electric field as a function of the square root of the electric field $\left[\ln (\mathrm{J} / \mathrm{E})\right.$ vs. $\left.\mathrm{E}^{1 / 2}\right]$ and a logarithm of the current density versus the square root of electric field $[\ln (J)$ vs. $\left.\mathrm{E}^{1 / 2}\right]$, respectively. A linear fitting appears while the applied electric field $\left(\mathrm{E}^{1 / 2}\right)$ in the range of $0.5-1.3(\mathrm{MV} / \mathrm{cm})^{1 / 2}$. For F-P emission, the slope of the straight line is 10.4 and 18.7 for $\mathrm{Hf}_{0.6} \mathrm{La}_{0.4} \mathrm{O}_{\mathrm{x}} / \mathrm{GaAs}(111)$ and $\mathrm{Hf}_{0.6} \mathrm{La}_{0.4} \mathrm{O}_{\mathrm{x}} / \mathrm{GaAs}(100)$, respectively. As to Schottky emission, the slope for $\mathrm{Hf}_{0.6} \mathrm{La}_{0.4} \mathrm{O}_{\mathrm{x}} /$ $\operatorname{GaAs}(111) \mathrm{A}$ and $\mathrm{Hf}_{0.6} \mathrm{La}_{0.4} \mathrm{O}_{\mathrm{x}} / \mathrm{GaAs}(100)$ is 12.6 and 21.5, respectively. The dynamic dielectric constant $\left(\varepsilon_{\mathrm{r}}\right)$ could be extracted from the slope of the linear region. The slope of 21.5 for $\mathrm{Hf}_{0.6} \mathrm{La}_{0.4} \mathrm{O}_{\mathrm{x}} / \mathrm{GaAs}(100)$ and 12.6 for $\mathrm{Hf}_{0.6} \mathrm{La}_{0.4} \mathrm{O}_{\mathrm{x}} /$ GaAs(111)A in Schottky emission is closer to the dielectric constant which is extracted by the $\mathrm{C}-\mathrm{V}$ measurement. This indicates that when the $\mathrm{E}^{1 / 2}$ is in the range of $0.5-1.3(\mathrm{MV} / \mathrm{cm})^{1 / 2}$, Schottky emissions would be the dominant leakage mechanism in $\mathrm{Hf}_{0.6} \mathrm{La}_{0.4} \mathrm{O}_{\mathrm{x}}$ films on $\mathrm{GaAs}(100)$ and $\operatorname{GaAs}(111)$ due to a substrate injection. ${ }^{25}$ In general, the electrons generated under positive gate bias could be from the interfaces states, traps in depletion region and back electrode of substrate. We consider that the underestimate $\varepsilon_{\mathrm{r}}$ value is due to the existence of low permittivity interfacial layer between $\mathrm{Hf}_{0.6} \mathrm{La}_{0.4} \mathrm{O}_{\mathrm{x}}$ film and GaAs substrate.

\section{SUMMARY AND CONCLUSIONS}

$\mathrm{Hf}_{0.6} \mathrm{La}_{0.4} \mathrm{O}_{\mathrm{x}}$ film was successfully deposited on GaAs(111)A and GaAs(100) substrates by the PEALD method in which $\mathrm{Hf}\left[\mathrm{N}\left(\mathrm{CH}_{3}\right)\left(\mathrm{C}_{2} \mathrm{H}_{5}\right)\right]_{4}$ and $\mathrm{La}\left[\mathrm{N}(\mathrm{TMS})_{2}\right]_{3}$ were employed as precursor and oxygen plasma as oxidant. Microstructure analysis shows a smooth interface and a reduction of interfacial layer between the $\mathrm{Hf}_{0.6} \mathrm{La}_{0.4} \mathrm{O}_{\mathrm{x}}$ films and the $\mathrm{GaAs}(111) \mathrm{A}$ substrates. XPS results indicated a reduction of 
$\mathrm{Ga}_{2} \mathrm{O}_{3}$ and arsenic oxides in the interfacial layer between $\mathrm{Hf}_{0.6} \mathrm{La}_{0.4} \mathrm{O}_{\mathrm{x}}$ and $\mathrm{GaAs}(111) \mathrm{A}$. Electrical properties of $\mathrm{Pt} / \mathrm{Hf}_{0.6} \mathrm{La}_{0.4} \mathrm{O}_{\mathrm{x}} / \mathrm{n}-\mathrm{GaAs}(111) \mathrm{A}$ MIS capacitors show a reduction of $\mathrm{D}_{\mathrm{it}}$ and leakage current comparing with the capacitor fabricated on $\operatorname{GaAs}(100)$.

${ }^{1}$ M. Xu, Y. Q. Wu, O. Koybasi, T. Shen, and P. D. Ye, Appl. Phys. Lett. 94, 212104 (2009).

${ }^{2}$ Y. Urabe, N. Miyata, H. Ishii, T. Itatani, T. Maedam, T. Yasuda, H. Yamada, N. Fukuhara, M. Hata, M. Yokoyama, N. Taoka, N. Takenaka, and S. Takagi, Tech. Dig. -Int. Electron Devices Meet. 6.5.1 (2010).

${ }^{3}$ S. Koveshnikov, W. Tasi, I. Ok, J. C. Lee, V. Torkanov, M. Yakimov, and S. Oktyabrsky, Appl. Phys. Lett. 88, 022106 (2006).

${ }^{4}$ M. M. Frank, G. D. Wilk, D. Starodub, T. Gustafsson, E. Garfunkel, Y. J. Chabal, J. Grazul, and D. A. Muller, Appl. Phys. Lett. 86, 152904 (2005).

${ }^{5}$ A. Dimoulas, G. Vellianitis, G. Mavrou, G. Apostolopoulos, A. Travlos, C. Wiemer, M. Fanciulli, and Z. M. Rittersma, Appl. Phys. Lett. 85, 3205 (2004).

${ }^{6}$ G. Seguini, S. Spiga, E. Bonera, M. Fanciulli, A. R. Huamantinco, C. J. Forst, C. R. Ashman, P. E. Blochl, A. Dimoulas, and G. Mavrou, Appl. Phys. Lett. 88, 202903 (2006).

${ }^{7}$ S. D. Elliott, Surf. Coat. Technol. 201, 9076 (2007).

${ }^{8}$ Y. Yamamoto, K. Kita, K. Kyuno, and A. Toriumi, Appl. Phys. Lett. 89, 032903 (2006).

${ }^{9}$ D. Liu, K. Tse, and J. Robertson, Appl. Phys. Lett. 90, 062901 (2007).

${ }^{10}$ V. Narayanan, V. Paruchuri, N. Bojarczuk, B. Linder, B. Doris, Y. Kim, S. Zafar, J. Stathis, S. Brown, J. Arnold, M. Copel, M. Steen, E. Cartier, A. Callegari, P. Jamison, J.-P. Locquet, D. Lacey, Y. Wang, P. Batson, P. Ronsheim, R. Jammy, and M. Chudzik, Tech. Dig. VLSI Symp. 178 (2006).
${ }^{11}$ W. He, D. S. H. Chan, S.-J. Kim, Y.-S. Kim, S.-T. Kim, and B. J. Cho, J. Electrochem. Soc. 155(10), G189-G193 (2008).

${ }^{12}$ D. Shahrjerdi, M. M. Oye, A. L. Holmes, and S. K. Banerjee, Appl. Phys. Lett. 89, 043501 (2006).

${ }^{13}$ Y. C. Chang, C. Merckling, J. Penaud, C. Y. Lu, W. E. Wang, J. Dekoster, M. Meuris, M. Caymax, M. Heyns, J. Kwo, and M. Hong, Appl. Phys. Lett. 97, 112901 (2010).

${ }^{14}$ K. Kobashi, T. Nagata, A. Ogura, T. Nabatame, and T. Chikyow, J. Appl. Phys. 114, 014106 (2013).

${ }^{15}$ H. L. Lu, X. L. Wang, M. Sugiyama, and Y. Shimogaki, Appl. Phys. Lett. 95, 212102 (2009).

${ }^{16}$ D. Marx, H. Asahi, X. F. Liu, M. Higashiwaki, A. B. Villaflor, K. Miki, K. Yamamoto, S. Gonda, S. Shimomura, and S. Hiyamizu, J. Cryst. Growth 150, 551 (1995).

${ }^{17}$ Y. Y. Mi, S. J. Wang, J. W. Chai, J. S. Pan, A. C. H. Huan, N. Ning, and C. K. Ong, Appl. Phys. Lett. 89, 202107 (2006).

${ }^{18}$ T. Das, C. Mahata, C. K. Maiti, E. Miranda, G. Sutradhar, and P. K. Bose, Appl. Phys. Lett. 98, 022901 (2011).

${ }^{19}$ M. Passlack, M. Hong, and J. P. Mannaerts, Appl. Phys. Lett. 68(8), 1099 (1996).

${ }^{20}$ K. J. Yang and C. M. Hu, IEEE Trans. Electron Devices 46(7), 1500 (1999).

${ }^{21}$ A. Ali, H. Madan, S. Koveshnikov, S. Oktyabrsky, R. Kambhampati, T. Heeg, D. Schlom, and S. Datta, IEEE Trans. Electron Devices 57, 742 (2010).

${ }^{22}$ K. S. K. Kwa, S. Chattopadhyay, N. D. Jankovic, S. H. Olsen, L. S. Driscoll, and A. G. O'Neill, Semicond. Sci. Technol. 18, 82 (2003).

${ }^{23}$ E. H. Nicollian and A. Goetzberger, Bell Syst. Tech. J. 46, 1055 (1967).

${ }^{24}$ S. M. Sze et al., Physics of Semiconductor Devices (Wiley, New York, 2007).

${ }^{25}$ K. Y. Cheong, J. H. Moon, H. J. Kim, W. Bahng, and N.-K. Kim, J. Appl. Phys. 103, 084113 (2008). 